\title{
ИССЛЕДОВАНИЕ ЭФФЕКТИВНОСТИ МИКРОВОЛНОВОГО КИСЛОТНОГО РАЗЛОЖЕНИЯ ДЛЯ ГЕОЛОГИЧЕСКИХ ОБРАЗЦОВ
}

\author{
Кравченко А.А. ${ }^{1,2}$, Николаева И.В. $^{2}$, Палесский С.В. ${ }^{2}$ \\ ${ }^{1}$ Новосибирский национальный исследовательский государственный университет, \\ Новосибирск, Россия \\ ${ }^{2}$ ФГБУН Институт геологии и минералогии им. В.С. Соболева СО РАН, \\ Новосибирск, Россия \\ a.kravchenko4@g.nsu.ru
}

DOI: 10.26902/ASFE-11_110

Микроволновое кислотное разложение характеризуется высокой производительностью и экономичностью, однако этот способ не нашел широкого применения для геологических пород, поскольку не всегда гарантирует вскрытия сложной силикатной матрицы. Использование этого метода разложения для основных и ультраосновных пород обусловлено тем, что исследуемые породы характеризуются относительно низким содержанием силикатов (менее 50-60 \%) и следовым уровнем определяемых примесных элементов, что предполагает необходимость разработки методики анализа с пределами обнаружения на уровне 0.0005-0.01 мкг/г $[1,2]$.

Целью настоящей работы является исследование эффективности микроволнового кислотного разложения основных, ультраосновных и кислых пород с последующим определением примесных элементов в полученных растворах методом масс-спектрометрии с индуктивно-связанной плазмой (МС-ИСП).

На основе результатов, полученных в серии экспериментов с изменением условий кислотного разложения исследуемых образцов (температура, давление, соотношение используемых кислот, масса навески образца) в микроволновой системе MARS-5, выбраны оптимальные условия пробоподготовки. Измерения были выполнены на ИСП массспектрометре с двойной фокусировкой ELEMENT, c использованием необходимого разрешения для отделения сигналов от спектральных наложений. При расчете концентраций для учета матричного влияния применяли внешнюю градуировку по многоэлементным стандартным растворам с имитацией кислотного состава проб после разложения, в качестве внутреннего стандарта использовали индий. Применимость разработанной методики для анализа основных и ультраосновных пород доказана на основе результатов определения 32 элементов ( $\mathrm{Sc}, \mathrm{V}, \mathrm{Cr}, \mathrm{Co}, \mathrm{Ni}, \mathrm{Cu}, \mathrm{Zn}, \mathrm{Rb}, \mathrm{Sr}, \mathrm{Y}, \mathrm{Zr}, \mathrm{Nb}, \mathrm{Cs}, \mathrm{Ba}, 14 \mathrm{P} 3 Э, \mathrm{Hf}, \mathrm{Ta}, \mathrm{Th}, \mathrm{U}$ ) в геологических стандартных образцах BHVO-2 и BCR-2 (базальты), UB-N (серпентинит), JP-1 (перидотит). Погрешности определения составили 2.4 до 12.4 \% для образцов BHVO-2, BCR2 и UB-N, и от 5 до 32\% для образца JP-1, последнее связано с близостью определяемых концентраций некоторых элементов к пределам обнаружения. Показана невозможность разложения образцов кислых пород в данных условиях.

Также получены первые результаты кислотного разложения геологических образцов в микроволновой системе UltraWAVE, которая позволяет работать при более высоких температурах и давлениях, проводится сравнение возможностей микроволновых систем MARS-5 и UltraWAVE.

\section{Сиисок литературы}

1. Magaldi T., Navarro M., Enzweiler J. Assessment of Dissolution of Silicate Rock Reference Materials with Ammonium Bifluoride and Nitric Acid in a Microwave Oven // Geostandards and Geoanalytical Research. - 2019. - T. 43, № 1. - C. 189-208.

2. Fedyunina N., Seregina I., Bolshov M., Okina O., Lyapunov S. Investigation of the efficiency of the sample pretreatment stage for the determination of the Rare Earth Elements in rock samples by inductively coupled plasma mass spectrometry technique // Analytica Chimica Acta. - 2012. - T. 713. - C. 97-102. 